\title{
Assessment of coagulation with $6 \%$ hydroxyethyl starch 130/0.4 in cesarean section
}

\author{
Chung-Sik Oh${ }^{1}$, Tae-Yun Sung ${ }^{2}$, Seong-Hyop Kim, Duk-Kyung Kim¹, Jeong-Ae Lim , and Nam-Sik Woo ${ }^{1}$ \\ Department of Anesthesiology and Pain Medicine, ${ }^{1}$ Konkuk University Medical Center, Konkuk University School of Medicine, Seoul, \\ ${ }^{2}$ Konyang University Hospital, Daejeon, Korea
}

Background: Third-generation hydroxyethyl starch (HES) solutions have been developed to minimize negative effects on hemostasis. In normal pregnancy, the coagulation activity increases, reaching a maximum around term. This study examined the effects of hemodilution with HES 130/0.4 (6\%) on blood coagulation in parturients in vivo and in vitro.

Methods: Forty parturients scheduled for cesarean sections were assigned randomly to receive either 500 or 1,000 $\mathrm{ml}$ of HES 130/0.4 (6\%). Rotation thromboelastometry $\left(\right.$ ROTEM $\left.^{\circledR}\right)$ measurements were performed before and after administering HES 130/0.4 (6\%). In addition, blood samples obtained from 20 randomly selected parturients were diluted $10 \%$ to $40 \%$ using HES 130/0.4 (6\%), and ROTEM ${ }^{\circledR}$ measurements were performed before and after dilution. The changes from baseline and the effects of dilution were analyzed by ROTEM ${ }^{\circledR}$ parameters.

Results: Infusions of 500 or 1,000 ml of HES 130/0.4 (6\%) in the parturients altered the clot formation time, $\alpha$ angle, and maximal clot firmness, although all remained within normal ranges. HES 130/0.4 (6\%) affected in vitro blood coagulation in parturients' blood containing 10, 20,30, and 40\% HES. The clotting time was prolonged at each dilution percentage, but remained within the normal range. Other parameters showed an impairment of the coagulation system.

Conclusions: Blood coagulation in parturients may be compromised at high dilution ratios of HES 130/0.4 (6\%) to blood. Nevertheless, the infusion of 1,000 ml of HES 130/0.4 (6\%) in normal parturients did not significantly affect blood coagulation. (Korean J Anesthesiol 2012; 62: 337-342)

Key Words: Cesarean section, Coagulation, Hydroxyethyl starch, Pregnancy.

Received: June 8, 2011. Revised: August 28, 2011. Accepted: September 2, 2011.

Corresponding author: Tae-Yun Sung, M.D., Department of Anesthesiology and Pain Medicine, Konyang University Hospital, 685, Gasoowondong, Seo-gu, Daejeon 302-718, Korea. Tel: 82-42-600-9316, Fax: 82-42-545-2132, E-mail: unt1231@naver.com

(c) This is an open-access article distributed under the terms of the Creative Commons Attribution Non-Commercial License (http:// creativecommons.org/licenses/by-nc/3.0/), which permits unrestricted non-commercial use, distribution, and reproduction in any medium, provided the original work is properly cited. 


\section{Introduction}

Normal pregnancy is associated with changes in hemostasis, including an increase in the concentration of most clotting factors (fibrinogen, VII, VIII, X, XII), in particular fibrinogen and factor VII are markedly increased [1]. Although anticoagulant activity decreases, as seen by decreased protein $\mathrm{S}$ concentration and activated protein $\mathrm{C}$ resistance, fibrinolysis is impaired $[2,3]$. These hematologic alterations are probably beneficial in limiting blood loss at delivery.

In patients with severe intravascular fluid deficits prior to the arrival of blood for transfusion, colloids should be considered as the initial resuscitation fluid. Several colloid solutions are generally available. Unlike other synthetic colloids, hydroxyethyl starch (HES) is nonantigenic, and anaphylactoid reactions are rare. Although HES has additional negative effects on hemostasis, recent new HES solutions, medium molecular weight (130 kd) and low molar substitution (0.4), are assumed to have a lower effect on coagulation [4]. In normal pregnancy, the coagulation activity in maternal blood increases, reaching a maximum around term. However, there are only few studies that have investigated the effects of diluting parturient blood with HES 130/0.4 (6\%) in vivo and in vitro, using rotation thromboelastometry $\left(\right.$ ROTEM $\left.^{\circledR}\right)$.

ROTEM $^{\circledR}$ has been developed from standardized thrombelastogram. ROTEM ${ }^{\circledR}$ shows more rapid and stable results compared to thromboelastography ${ }^{\circledR}$ (TEG), and suggests proper guidelines for the diagnosis of coagulopathy in severe-bleeding expected surgeries.

This study compared baseline ROTEM ${ }^{\circledR}$ measurements between two parturient groups according to administration of different HES volume and examined the effects of hemodilution with HES 130/0.4 (6\%) on blood coagulation in parturients in vivo and in vitro.

\section{Materials and Methods}

\section{Study population}

This study was performed after obtaining approval from the Institutional Review Board at our center, and informed consent was obtained from all participants. We studied forty parturients who were scheduled for elective cesarean section and all were ASA physical status I-II. Parturients with a history of coagulation disorders, preeclampsia, placenta previa, multiple pregnancy, hemorrhage, current aspirin use, or heparin therapy were excluded from this study.

\section{Study design}

Blood samples were obtained from 40 parturients and baseline hemostatic data and ROTEM $^{\circledR}$ parameters were measured. Parturient groups were divided in to two groups. The first group received HES $500 \mathrm{ml}$ (Group HES 500), using two syringes, a $5 \mathrm{ml}$ venous blood sample was obtained from the antecubital vein without venous stasis from each volunteer before anesthetic induction. The first $3 \mathrm{ml}$ was discarded to avoid tissue contamination with tissue thromboplastin and the second $2 \mathrm{ml}$ was collected in a tube containing sodium citrate (Vacuette ${ }^{\circledR}$, Greiner Bio-One GmbH, Kremsmünster, Austria). After that, ROTEM ${ }^{\circledR}$ analysis was performed. The second group (Group HES 1000) received HES 1,000 $\mathrm{ml}$ using the same methods, and before anesthetic induction, a $2 \mathrm{ml}$ venous blood sample was obtained and ROTEM ${ }^{\circledR}$ analysis was performed. In addition, blood samples obtained from 20 randomly selected parturients were diluted 10, 20, 30, and 40\% using HES 130/0.4 (6\%), after which ROTEM ${ }^{\circledR}$ analysis was performed before and after dilution.

In all groups, endotracheal intubation was done after induction of anesthesia with $4 \mathrm{mg} / \mathrm{kg}$ thiopental sodium and $1.5 \mathrm{mg} / \mathrm{kg}$ succinylcholine, and then $0.05 \mathrm{mg} / \mathrm{kg}$ vecuronium was injected intravenously. During the surgery, mechanical ventilation was maintained using a mixture of $50 \%$ oxygen $(2 \mathrm{~L} /$ min) with sevoflurane $(0.7-1.2$ vol\%) and nitrous oxide (2 L/ $\min )$.

After placental expulsion, $100 \mu \mathrm{g}$ carbetocin, which is an oxytocin agonist, was injected intravenously for providing assistance to uterine contractions. In the group HES 500, after the operation started and the fetus was removed, $6 \%$ Voluven $^{\circledR}$ (Fresenius Kabi Korea, Seoul, Korea), which is a medium molecular weight HES with a molar substitution of 0.4 , was administrated in a volume of $500 \mathrm{ml}$ intravenously. In the group HES 1000, 6\% Voluven ${ }^{\circledR} 1,000 \mathrm{ml}$ was administrated intravenously. Immediately after administration of Voluven ${ }^{\circledR}$, $2 \mathrm{ml}$ venous blood samples were obtained from members of all groups in the same way as before anesthetic induced blood sampling. Samples were obtained from the peripheral vein, which is not the former blood sampling obtained. Following that, ROTEM ${ }^{\circledR}$ analysis was performed. The dropping rate of HES was to maintain the target hemodynamic range (mean arterial blood pressure $>60 \mathrm{mmHg}$, within $20 \%$ of baseline heart rate), during anesthesia, and end tidal $\mathrm{CO}_{2}$ concentration was maintained at $35-38 \mathrm{mmHg}$. In the two groups, additional $300 \mathrm{ml}$ Hartmann's solution was also given in the light of NPO times and intraoperative insensible loss. All patients were observed carefully by one anesthesiologist. There were no side effects, including anaphylactic reaction, generalized edema, or renal dysfunction. All blood samples for the study were collected in a tube containing sodium citrate. Samples were collected and analysed simultaneously at $37^{\circ} \mathrm{C}$ on a four-channel ROTEM ${ }^{\circledR}$ with InTEM $^{\circledR}$, which is an intrinsic 
coagulation system screening test and activates clot formation by means of $\mathrm{CaCl}_{2}$ and partial thromboplastin.

\section{Parameters of ROTEM ${ }^{\circledR}$}

Through the ROTEM ${ }^{\circledR}$ with InTEM ${ }^{\circledR}$ analysis, clotting time [CT, r (reaction time) in conventional TEG], clot formation time [CFT, $\mathrm{k}$ (kinetics) in conventional TEG], $\alpha$ angle [( $\alpha$ slope between $r$ and $k$ ) in conventional TEG] and maximum clot firmness [MCF, MA (maximum amplitude) in conventional TEG] were measured. CT is the time until the initiation of clotting. The results depended on the concentration of coagulation factors and the presence of inhibitors. CFT is the time from the initiation of clotting until amplitude of $20 \mathrm{~mm}$ is reached, and represents clot kinetics. $\alpha$-Angle is determined by the angle between the center line and tangent to the curve through an amplitude of $2 \mathrm{~mm}$, and this represents clot strengthening. MCF is the maximum amplitude of thromboelastogram, and it represents clot firmness. The known reference values are: for CT, $141.5 \pm 15.8 \mathrm{sec}$ (range: 100-240); for CFT, $71.0 \pm 18.5 \mathrm{sec}$ (range: $30-110$ ); for $\alpha$ angle, $76.5 \pm 3.3^{\circ}$ (range: 70-83); for MCF, $61.0 \pm 5.5 \mathrm{~mm}$ (range: $50-72$ ).

\section{Statistics}

The data were analysed using the Statistical Package for Social Science (SPSS for Windows, ver. 12.0; SPSS Inc, Chicago, IL, USA), and expressed as the mean \pm SD. Normally distri-

Table 1. Demographic and Obstetric Data of the Patients in This Study

\begin{tabular}{lcc}
\hline & HES $500(\mathrm{n}=20)$ & HES $1000(\mathrm{n}=20)$ \\
\hline Age $(\mathrm{yr})$ & $32.4 \pm 4.85$ & $34.4 \pm 2.48$ \\
Height $(\mathrm{cm})$ & $159 \pm 6.45$ & $161.7 \pm 3.74$ \\
Weight $(\mathrm{kg})$ & $66.95 \pm 10.96$ & $71.15 \pm 9.94$ \\
\hline
\end{tabular}

Values are expressed as mean \pm SD or number of patients. buted data (tested by the Kolmogorov-Smirnov test) were analyzed using the Student's t-test, paired t-test and repeated measure analysis of variance, as appropriate. A paired t-test was performed to analyse changes from baseline within each group. Student's t-test was performed to compare between the two groups. Repeated measure analysis of variance was used to compare ROTEM ${ }^{\circledR}$ parameters according to progressive in vitro hemodilution. A $\mathrm{P}$ value $<0.05$ was considered statistically significant.

\section{Results}

There were no significant differences between the two groups in terms of age, height, and weight (Table 1).

\section{Comparison of ROTEM ${ }^{\circledR}$ analysis in the parturient group according to HES administration volume}

There were no significant differences in the preoperative ROTEM $^{\circledR}$ analysis between group HES 500 and group HES 1000 (Table 2).

Administration of 500 or 1,000 ml of HES 130/0.4 (6\%) in the parturients prolonged the CFT and decreased the $\alpha$ angle and MCF. Although theses values remained within a normal reference range, they were statistically different (Table 2).

\section{Comparison of ROTEM ${ }^{\circledR}$ analysis in the parturient group according to hemodilution with HES in vitro}

HES 130/0.4 (6\%) was affected during in vitro blood coagulation in parturient blood containing 10, 20, 30, and 40\% HES. The CT and CFT were significantly prolonged. $\alpha$-Angle and MCF were significantly decreased at each dilution percentage (Table 3, Fig.1). Although CT was significantly increased compare with the earlier dilution, it was the within normal range even at 40 dilution percentage. The $\alpha$ angle deviated from the normal range at a $10 \%$ dilution. CFT deviated from the normal

Table 2. Comparison of ROTEM ${ }^{\circledR}$ with InTEM ${ }^{\circledR}$ Data in the HES 500 and HES 1,000 Groups before and after Infusion of HES $500 \mathrm{ml}$ and 1,000 ml, Respectively

\begin{tabular}{|c|c|c|c|c|c|c|}
\hline & \multicolumn{3}{|c|}{ HES $500(n=20)$} & \multicolumn{3}{|c|}{ HES $1000(n=20)$} \\
\hline & Before infusion & After infusion & $P$ value & Before infusion & After infusion & $\mathrm{P}$ value \\
\hline CT (sec) & $141.6 \pm 20.1$ & $143.4 \pm 27.2$ & 0.828 & $142.8 \pm 18.0$ & $146.3 \pm 18.2$ & 0.546 \\
\hline CFT (sec) & $78.1 \pm 16.3$ & $102.7 \pm 20.0 *$ & 0.001 & $78.8 \pm 12.3$ & $103.0 \pm 15.3^{\dagger}$ & 0.001 \\
\hline$\alpha$ angle $\left(^{\circ}\right)$ & $75.4 \pm 2.7$ & $71.2 \pm 3.3^{*}$ & 0.001 & $73.5 \pm 4.2$ & $69.5 \pm 4.1^{\dagger}$ & 0.01 \\
\hline $\mathrm{MCF}(\mathrm{mm})$ & $65.5 \pm 5.4$ & $61.7 \pm 4.0^{*}$ & 0.002 & $63.6 \pm 4.2$ & $60.9 \pm 4.3^{\dagger}$ & 0.02 \\
\hline
\end{tabular}

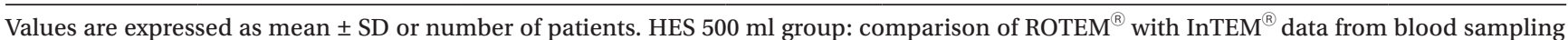
before and after infusion of HES $500 \mathrm{ml}$, HES 1,000 ml group: Comparison of ROTEM ${ }^{\circledR}$ with InTEM $^{\circledR}$ data from blood sampling before and after infusion of HES 1,000 ml, CT: clotting time, CFT: clot formation time, $\alpha$ angle: slope of tangent at 2 mm amplitude, MCF: maximum clot firmness. $* \mathrm{P}$ value $<0.05$ compared with before $\mathrm{HES} 500 \mathrm{ml}$ infusion. ${ }^{\dagger} \mathrm{P}$ value $<0.05$ compared with before $\mathrm{HES} 1,000 \mathrm{ml}$ infusion. 
Table 3. ROTEM $^{\circledR}$ with InTEM ${ }^{\circledR}$ Data in the Parturient Group before and after in vitro Hemodilution with HES $130 / 0.4$ (6\%)

\begin{tabular}{|c|c|c|c|c|c|}
\hline & $\begin{array}{l}\text { Baseline } \\
(n=20)\end{array}$ & $\begin{array}{l}10 \% \text { dilution } \\
\quad(\mathrm{n}=20)\end{array}$ & $\begin{array}{l}20 \% \text { dilution } \\
\qquad(\mathrm{n}=20)\end{array}$ & $\begin{array}{l}30 \% \text { dilution } \\
\quad(\mathrm{n}=20)\end{array}$ & $\begin{array}{l}40 \% \text { dilution } \\
\quad(\mathrm{n}=20)\end{array}$ \\
\hline CT (sec) & $141.9 \pm 19.3$ & $145.2 \pm 12.0^{*}$ & $172.1 \pm 9.5^{*}$ & $181.1 \pm 8.4^{*}$ & $196.0 \pm 8.5^{*}$ \\
\hline CFT (sec) & $78.2 \pm 14.5$ & $103.1 \pm 12.4^{*}$ & $134.9 \pm 16.9^{*}$ & $157.0 \pm 10.6^{*}$ & $246.6 \pm 24.2^{*}$ \\
\hline$\alpha$ angle $\left({ }^{\circ}\right)$ & $74.2 \pm 3.9$ & $64.9 \pm 2.0^{*}$ & $63.6 \pm 5.5^{*}$ & $58.8 \pm 3.5^{*}$ & $54.8 \pm 3.2^{*}$ \\
\hline $\operatorname{MCF}(\mathrm{mm})$ & $64.3 \pm 4.7$ & $61.9 \pm 2.2^{*}$ & $58.4 \pm 4.4^{*}$ & $56.1 \pm 4.4^{*}$ & $49.3 \pm 3.7^{*}$ \\
\hline
\end{tabular}

Values are expressed as mean \pm SD. CT: clotting time, CFT: clot formation time, $\alpha$ angle: slop of tangent at 2 mm, amplitude, MCF: maximum clot firmness. Baseline: ROTEM ${ }^{\circledR}$ with InTEM ${ }^{\circledR}$ anlaysis data before infusion of HES in the parturient blood. 10\% dilution: ROTEM ${ }^{\circledR}$ with InTEM $^{\circledR}$ anlaysis data, in vitro, after $10 \%$ dilution in the parturient blood with HES (130/0.4). 20\% dilution: ROTEM $^{\circledR}$ with InTEM $^{\circledR}$ anlaysis data, in vitro, after $20 \%$ dilution in the parturient blood with HES (130/0.4). $30 \%$ dilution: ROTEM ${ }^{\circledR}$ with InTEM ${ }^{\circledR}$ anlaysis data, in vitro, after $30 \%$ dilution in the parturient blood with HES $(130 / 0.4) .40 \%$ dilution: ROTEM ${ }^{\circledR}$ with InTEM $^{\circledR}$ anlaysis data, in vitro, after $40 \%$ dilution in the parturient blood with HES $(130 / 0.4) .{ }^{*} \mathrm{P}$ value $<0.05$ compared with before dilution of parturient's blood.

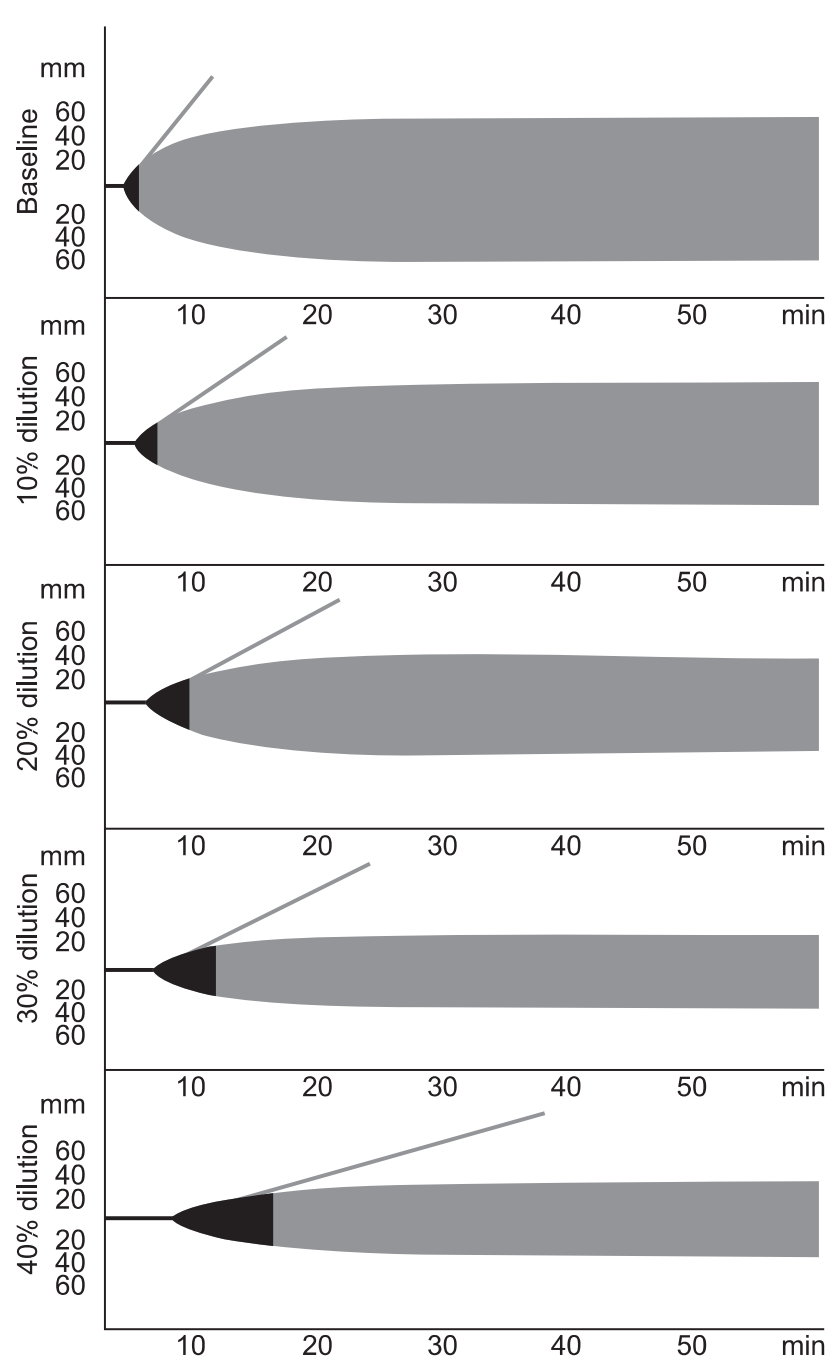

Fig. 1. In vitro, ROTEM ${ }^{\circledR}$ with InTEM ${ }^{\circledR}$ analysis graph before and after hemodilution with HES $(130 / 0.4)$. The examples of the study result of Table 3 . The clotting time (CT) and clot formation time (CFT) were significantly prolonged where $\alpha$ angle and maximal clot firmness (MCF) were significantly decreased at each dilution percentage. $\alpha$ angle deviated from the normal range at $10 \%$ dilution. CFT deviated from the normal range at $20,30,40 \%$ dilution and MCF deviated from the normal range at $40 \%$ dilution. range at 20, 30, and $40 \%$ dilution and MCF deviated from the normal range at $40 \%$ dilution.

\section{Discussion}

Normal pregnancy is associated with changes in all aspects of hemostasis. During pregnancy, the coagulation factors VII, VIII, IX, X, XII and von Willebrand factors rise significantly, accompanied by a pronounced increase in fibrinogen levels, which increase up to two times above those of non-pregnant levels, whereas antithrombin III levels decrease [1-3]. Anticoagulant concentration and fibrinolytic activity decrease, thus causing a state of hypercoagulability to exist compared with non-pregnant women.

In relation to thrombosis, quantitative analysis of coagulation factors such as platelet count, prothrombin time (PT) and activated partial thromboplastin time (aPTT) may only represent a part of the blood coagulation process.

Thromboelastography does not show quantitative values such as standard coagulation tests, but it allows for the analysis of whole blood coagulation mechanisms. It also measures the viscoelastic properties of blood as well as coagulation factor and platelet activity from a single blood sample [4]. Thromboelastography $\left(\right.$ TEG $^{\circledR}$ ) was first described by Hatrert (1948) [5], and has continued to evolve for the evaluation of coagulation function of whole blood. Using whole blood, $\mathrm{TEG}^{\circledR}$ measures the viscoelasticity of blood and records the graphical representation of the fibrin polymerization process. In addition, $\mathrm{TEG}^{\circledR}$ provides information including the initiation of coagulation, fibrin-platelet interaction, clot firmness, and fibrinolysis. However, in specific circumstances, coagulation is not initiated by a biochemical agonist, and the shortcomings are that it takes a long time to obtain results and is susceptible to vibrations [4]. As a modified form of conventional thromboelastography, ROTEM ${ }^{\circledR}$ (modified rotation thromboelastogram analyzer) has been used recently to observe the formation of thrombi, using an optical detector 
system, instead of the torsion wire used in $\mathrm{TEG}^{\circledR}[6]$. Therefore, ROTEM $^{\circledR}$ leads to fewer errors in the sample, and a more rapid measurement (within $30 \mathrm{~min}$ ). For this reason, ROTEM $^{\circledR}$ is increasingly being used in clinical practice.

This study aimed to compare qualitative coagulation tendency with HES infusion via ROTEM ${ }^{\circledR}$ analysis in healthy parturients undergoing a cesarean section. Also, to evaluate hemodilutional effects of HES, we compared the effects of progressive $(10,20,30$, and $40 \%)$ in vitro hemodilution with HES using ROTEM $^{\circledR}$ analysis. The background of this study was that if we assume a body weight of $60 \mathrm{~kg}$ for a parturient, estimated total blood volume in the parturient may be $5,400 \mathrm{ml}(90 \mathrm{ml} /$ $\mathrm{kg}$ ) because of increased blood volume [7]. As a result, $10 \%$ hemodilution corresponds roughly to $540 \mathrm{ml}$ HES infusion. Volumes of 20,30 , and $40 \%$ hemodilution correspond to 1,080 , 1,620, 2,160 ml HES infusion, respectively.

HES 130/0.4 (6\%) is considered a general value, and its maximal or safe dosage is $20 \mathrm{ml} / \mathrm{kg}$, yet this is just the manufacturer's guideline, and is not supported by published data $[8,9]$. In addition, even though numerous studies have been performed to evaluate the effects of HES 130/0.4 (6\%) on coagulation [10-16], few studies have been conducted to evaluate the safety and efficacy of HES 130/0.4 (6\%) in vivo and in vitro, especially in parturients using ROTEM $^{\circledR}$ analysis [17].

HES has a negative effect on blood coagulation according to degree of molar substitution and mean molecular weight [18]. The third-generation HES 130/0.4, appears to have relatively fewer negative effects on hemostasis compared to first-generation high mean molecular weight and high molar substitution (450/0.7) [11]. However, despite a lower molecular weight and molar substitution HES, hemodilution after large volume replacement leads to the dilution of red blood cells, platelets, and coagulation factors. Also, additional surgical bleeding, hypothermia, and inflammatory reactions can cause the delay of blood coagulation. Besides dilutional coagulopathy, HES decreases fibrinogen concentration, activity of factor VII, VIII, IX, and von Willebrand factor levels [19], as well as reduced platelet function by coating the platelet surface or inducing platelet damage [20].

Butwick and Carvalho [21], have demonstrated that statistically significant increases in TEG parameters ( $\mathrm{r}$ and $\mathrm{k}$ times) following preloading with $500 \mathrm{ml}$ HES 670/0.75 (6\%) in pregnant patients prior to spinal anesthesia for elective cesarean delivery, although these post-fluid loading TEG parameters remained within a normal reference range. In the present in vivo study, administration of $500 \mathrm{ml}$, or higher volumes than previous study [21] of up to $1,000 \mathrm{ml}$ of HES $130 / 0.4$ (6\%) in the parturients altered ROTEM ${ }^{\circledR}$ parameters, prolonged clot formation time (CFT) and decreased $\alpha$ angle, and maximal clot firmness (MCF). These values remained within a normal reference range. Furthermore, in an in vitro study, CT prolonged and MCF decreased but also remained within the normal range of up to 40 and $30 \%$ dilution, respectively. Our results indicate that, in parturients, initial fibrin formation and the strength of blood clots with clot firmness were not significantly affected by the administration of HES 130/0.4 (6\%) up to 1,000 ml volume. In addition, we can cautiously infer that the reasons behind why the coagulation factors and fibrinogen levels increased in parturients may be related to this result. Thus, if the amount of HES administration is adjusted within the correct range in a clinical infusion dose, HES does not have a major influence on bleeding in parturients. In the case of surgery of parturients that show the hypercoagulable state fundamentally, we expect that the permissible limit of HES administration can be larger until a normal coagulable state.

Meanwhile, the $\alpha$ angle and CFT deviated from the normal range in vitro at a relatively lower dilution percentage compared with CT and MCF, and this shows the administration of HES $130 / 0.4$ at $30 \%$ dilution can impair fibrin kinetics and polymerization in parturient blood.

However, extrapolation of in vitro data with the data found in the clinical setting is difficult, because results from the in vitro studies do not necessarily concur with the situation in surgery. In our in vivo study, the $\alpha$ angle and CFT remained within the normal range even after 1,000 $\mathrm{ml}$ infusion of HES, which corresponds to roughly $20 \%$ dilution in the in vitro study. However, these results deviated from the normal range in our in vitro study at the same dilution percentage. We assumed that this result was related to a neuroendocrine stress response and the effect of blood coagulation by vascular endothelial cell which occur during surgery. Surgery causes changes in hemostasis by neuroendocrine stress, increased platelet reactivity and decreases circulation coaugulation inhibitors, finally causing a generalized hypercoagulable state [22]. The potential effects of these coagulation changes in parturients on clinical outcomes remain unclear.

Jamnicki et al. [23], demonstrated the effects of in vitro hemodilution (30\% and $60 \%$ ) on blood coagulation in patients receiving HES 130/0.4 (6\%) and 200/0.5 (6\%) solutions using $\mathrm{TEG}^{\circledR}$. As a result, $\mathrm{r}$ and $\mathrm{k}$ increased, and MA and $\alpha$ angle decreased progressively with an increasing degree of hemodilution in both HES solution. This finding was in accordance with our results. We found that HES 130/0.4 (6\%) progressively impaired in vitro blood coagulation in parturient blood containing 10, 20, 30, and 40\% HES. This indirectly showed that the administration of HES $130 / 0.4(6 \%)$ to the parturients lead to impairment of coagulation in proportion to the amount of HES volume. Particularly, in addition to coagulation factor impairment induced by HES administration, massive fluid administration leads to dilutional coagulopathy, which is a 
factor of increasing the blood loss. Thus, in relation to dilutional coagulopathy, clinical studies are necessary to fully evaluate the hemostatic influence of the large volume HES 130/0.4 administration in parturients to assess the clinical relevance of our findings.

In conclusion, blood coagulation in parturients may be compromised at high dilution ratios of medium molecular weight, a lower molar substitution HES 130/0.4 (6\%) to blood. Nevertheless, the infusion of $1000 \mathrm{ml}$ of HES 130/0.4 (6\%) in normal parturients did not significantly affect blood coagulation.

\section{References}

1. Miller RD. Miller's anesthesia. 7th ed. Philadelpia, Elsevier Churchill livingstone. 2009, p 2205.

2. Hellgren M. Hemostasis during normal pregnancy and puerperium. Semin Thromb Hemost 2003; 29: 125-30.

3. Brenner B. Haemostatic changes in pregnancy. Thromb Res 2004; 114: 409-14.

4. Whitten CW, Greilich PE. Thromboelastography: past, present, and future. Anesthesiology 2000; 92: 1223-5.

5. Hartert H. Blutgerinnungsstudien mit der thrombelastographie, einem neuen untersuchungsverfahren . Klin Wochenschr 1948; 26 : 577-83.

6. Ganter MT, Hofer CK. Coagulation monitoring: current techniques and clinical use of viscoelastic point-of-care coagulation devices. Anesth Analg 2008; 106: 1366-75.

7. Morgan GE. Clinical anesthesiology. 7th ed. New York, McGrawHill. 2006, p 876.

8. Warren BB, Durieux ME. Hydroxyethyl starch: safe or not? Anesth Analg 1997; 84: 206-12.

9. Wiedermann CJ. Hydroxyethyl starch 130/0.4: does "modern" mean safe? Anesth Analg 2009; 109: 1346-7.

10. Konrad CJ, Markl TJ, Schuepfer GK, Schmeck J, Gerber HR. In vitro effects of different medium molecular hydroxyethyl starch solutions and lactated Ringer's solution on coagulation using SONOCLOT. Anesth Analg 2000; 90: 274-9.

11. Gallandat Huet RC, Siemons AW, Baus D, van Rooyen-Butijn WT, Haagenaars JA, van Oeveren W, et al. A novel hydroxyethyl starch (Voluven) for effective perioperative plasma volume substitution in cardiac surgery. Can J Anaesth 2000; 47: 1207-15.

12. Langeron O, Doelberg M, Ang ET, Bonnet F, Capdevila X, Coriat P. Voluven, a lower substituted novel hydroxyethyl starch (HES 130/0.4), causes fewer effects on coagulation in major orthopedic surgery than HES 200/0.5. Anesth Analg 2001; 92: 855-62.

13. Franz A, Bräunlich P, Gamsjäger T, Felfernig M, Gustorff B, KozekLangenecker SA. The effects of hydroxyethyl starches of varying molecular weights on platelet function. Anesth Analg 2001; 92: 1402-7.

14. Haisch G, Boldt J, Krebs C, Suttner S, Lehmann A, Isgro F. The influence of a new hydroxyethyl starch preperation (6\% HES 130/0.4) on coagulation in cardiac surgical patients. J Cardiothorac Vasc Anesth 2001; 15: 316-21.

15. Haisch G, Boldt J, Krebs C, Kumle B, Suttner S, Schulz A. The influence of intravascular volume therapy with a new hydroxyethyl starch preparation (6\% HES 130/0.4) on coagulationin patients undergoing major abdominal surgery. Anesth Analg 2001; 92: 56571 .

16. Boldt J, Haisch G, Suttner S, Kumle B, Schellhaass A. Effects of a new modified, balanced hydroxyethyl starch preparation (Hextend) on measures of coagulation. Br J Anaesth 2002; 89: 722-8.

17. Sharma SK, Philip J, Wiley J. Thromboelastographic changes in healthy parturients and postpartum women. Anesth Analg 1997; 85: 94-8.

18. de Jonge E, Levi M. Effects of different plasma substitutes on blood coagulation: a comparative review. Crit Care Med 2001; 29: 1261-7.

19. Mittermayr M, Streif W, Haas T, Fries D, Velik-Salchner C, Klingler A, et al. Hemostatic changes after crystalloid or colloid fluid administration during major orthopedic surgery: the role of fibrinogen administration. Anesth Analg 2007; 105: 905-17.

20. Boldt J, Suttner S. Plasma substitutes. Minerva Anestesiol 2005; 71: 741-58.

21. Butwick A, Carvalho B. The effect of colloid and crystalloid preloading on thromboelastography prior to Cesarean delivery. Can J Anaesth 2007; 54: 190-5.

22. Rosenfeld BA, Faraday N, Campbell D, Dise K, Bell W, Goldschmidt P. Hemostatic effects of stress hormone infusion. Anesthesiology 1994; 81: 1116-26.

23. Jamnicki M, Zollinger A, Seifert B, Popovic D, Pasch T, Spahn DR. Compromised blood coagulation: an in vitro comparison of hydroxyethyl starch 130/0.4 and hydroxyethyl starch 200/0.5 using thromboelastography. Anesth Analg 1998; 87: 989-93. 